Trends in Applied Sciences Research, 2007

ISSN 1819-3579

(c) Academic Joumals Inc., USA

\title{
Extraction and Identification of Alkaloids of the Ipomoea fistulosa (Aguapei or Mandiyurá) of Argentina
}

\author{
${ }^{1}$ Luciana Cholich, ${ }^{1}$ Edgar Bogado, ${ }^{2}$ Nelly Jorge, ${ }^{1}$ Ofelia Acosta and ${ }^{3}$ Eduardo A. Castro \\ ${ }^{1}$ Cátedra de Farmacología, Facultad de Ciencias Veterinarias \\ ${ }^{2}$ Área de Química Física, Química Física I, Facultad de Ciencias Exactas y Naturales y \\ Agrimensura, Universidad Nacional del Nordeste (U.N.N.E.), Corrientes, Argentina \\ ${ }^{3}$ INIFTA, Theoretical Chemistry Division, Department of Chemistry, \\ Faculty of Exact Sciences, La Plata National University, \\ Suc.4, C.C. 16, La Plata 1900, Buenos Aires, Argentina
}

\begin{abstract}
The classical toxic effect produced by this Ipomoea fistulosa is due to the accumulation of oligosacharides in various tissues cell cytoplasm, mainly nervous, liver and lymphatic tissues, that leads to the cell vacuolitation. These effects are attributed to the presence of substances called swansonina and calisteginas in the vegetables, which produce inhibition of enzymes liposomales responsible for the metabolic carbohydrates. In natural conditions, the plant is not consumed by the animals. Its consumption occurs alone in determined times of year, for lack of sufficient pasture and it is more frequent in young animals. Since standard literature does not register any data on the chemical analysis of the kind Ipomoea, we report here the results on the extraction, isolation and spectroscopic identification of the present alkaloids in this plant.
\end{abstract}

Key words: Alkaloids, Ipomoea fistulosa, IR spectrum

\section{Introduction}

The intoxication due to the consumption of toxic plants in animals of different species represents a constant economic risk for the people devoted to the production of agricultural goods and cattle raising tasks. The toxicity of a plant changes according to several factors: vegetable species and variety, time of year, phase of growth, type of ground where it grows, fertilisations, use of herbicides, etc Ipomoea fistulosa is a plant that belongs to the Convolvulaceae family, which is conformed by a large number of species. It is world-wide distributed, being found in Latin America from Colombia to Paraguay, Bolivia and Argentina. It is also found in Africa (de Balogh et al., 1999) and India (Nath and Pathak, 1995). In Argentina 6 species have been identified in the northeast region and Ipomoea fistulosa is a very abundant species. It is known in this region with the vulgar names of aguapié or mandiyurá (O’Donell, 1959). In Brazil, I. fistulosa is known as algodao brave, manjorana or canudo (Lorenzi, 1991). The same species in India produces allergic reactions in human beings, since its pollen constitutes a powerful allergen (Amal et al., 1998).

At the north zone of Argentina the Ipomea genus is found in a vast portion of the region but up to now the basic toxic components of this genus have not been studied in detail. Then, people do not know the corresponding risks when bovine cattle and other animals feed themselves when there is scarcity of pastures, giving rise to an economical expense for the bovine cattle producer.

Corresponding Author: Eduardo A. Castro, INIFTA, Theoretical Chemistry Division, Department of Chemistry, Faculty of Exact Sciences, La Plata National University, Suc.4, C.C. 16, La Plata 1900, Buenos Aires, Argentina 
The mandiyurá o aguapié is a plant that is found in large groups at the rivers and lake shores. It is a bush with a height up to $3 \mathrm{~m}$, few ramified; thick stems, fistulouses finely striated. Its flowers are light violet coloured, of great size and with a shape of bellflower, grouped in bunches of 2 or 3 units, with very bright colours. Their leaves are intense green coloured, in the shape of an arrowtip. The fruit is a capsule that is opened spontaneously when it is nature, it possesses few seeds, covered with silky, long hairs, that facilitate their dispersion by the wind (Austin, 1977).

The polyhydroxy alkaloids were isolated from the leaves, flowers and seeds of the Ipomoea carnea and characterized by gas chromatography-mass spectrometry. Affected animals were ataxic, with head tremors and nystagmus (de Balogh et al., 1999). The leaves were soaked in methanol for $16 \mathrm{~h}$ in Soxhet apparatus and the alkaloids fraction was purified by ion-exchange chromatography. Cromatographic separation of the leaf extract resulted in the isolation of swansonine, 2-epi-lentiginosine, calystegine $\mathrm{B}_{1}, \mathrm{~B}_{2}, \mathrm{~B}_{3}$ and $\mathrm{C}_{1}$ and N-methyl-trans-4-hydroxy-1proline (de Balogh et al., 1999; Haraguchi et al., 2003). The swansonine y calystegine $\mathrm{B}_{2}$ have been identified as constituents of the seeds from Ipomoea calobra by gas chromatography-mass spectrometry (Molyneux et al., 1995).

Swansonina is a potent inhibitor of the $\alpha$-mannosidase, whereas calystegine B1, B2 and C1 are potent inhibitors of the $\beta$-glucosidase (Ikeda et al., 2003).

Ipomea species produces a neurological disorder when consumed by livestock (Molyneux et al., 1995). Different organs from envenoming livestock were histolgically characterized by vacuolated cells (Hueza et al., 2005).

Chronic exposure of livestock to Ipomoea camea is clinically manifested by CNS signs, abnormal endocrine and gastrointestinal functions, alterations of the immune system and abnormal embryogenesis (Hueza et al., 2003).

In natural conditions, the plant is not consumed by the animals. Its consumption occurs alone in determined times of year, for the lack of sufficient pasture, being this more frequent in young animals (Méndez and Rief-Correa, 2000).

The continuous Soxhlet extractive method employed by authors is a method based on the decomposition of the alkaloid pyrrolidinic rings, so that we propose a methodology that improves the yielding without producing the decomposition of the alkaloids.

In Argentina, there is no data on the chemical analysis of the kind Ipomoea, so the purpose of this work is to report the experimental results on the extraction, isolation and identification of the present alkaloids in this plant. The last task has been accomplished via an IR spectroscopic study in order to give the main vibrational mode assignments.

The characterization of the components of Ipomea fistslosa in corrientes is very essential because determine the actual cause the dead of goat.

\section{Materials and Methods}

\section{Extraction and Isolation}

The Ipomea fistulosa leaves were collected from the cultivation made in the University Campus of the North-Est National University during Autumn. The species identification was made by technical people belonging the the Ivonne Institute, located at the Agrary Sciences Faculty belonging to this University.

The vegetable material was dried in stove to $60^{\circ} \mathrm{C}$ to constant weight and then it was pulverised and sifting to obtain a constant granulometry (sieve 30-40) degree. We weighed $2 \mathrm{~g}$ of vegetable material (leaves), we placed them in an Erlenmeyer and we added $100 \mathrm{~mL}$ of the solvent sulfuric ether. Then, we alkalinised with $10 \%$ ammonia $\left(\mathrm{NH}_{3}\right)$ leaving the mixture in soaking for 12 to $24 \mathrm{~h}$ and agitating it occasionally. After this time, we filtered the sample by a vacuum equipment and we placed it in a blister of decanting to carry out a series of washes with $2 \%$ sulfuric acid $\left(\mathrm{H}_{2} \mathrm{SO}_{4}\right)$. 
Once the acid solution was obtained, we alkalinised with $10 \%$ ammonia $\left(\mathrm{NH}_{3}\right)$. The final task was to add ether to obtain the organic solvent on the one hand and the acid solution on the other. Finally, we left to evaporate the solvent organic, precipitating the alkaloid that was dried and purified.

After obtaining the mixture of alkaloids, we proceeded to its identification by infrared spectrophotometry, using an infrared spectrum trade mark Nicolet. The IR spectrum was determined among the range $400-4000 \mathrm{~cm}^{-1}$, using the technique of diffuse refractancy with BrK as solvent.

\section{Results and Discussion}

In our investigation aerial parts of Ipomea fistulosa were extracted as already described (Wiedenfeld and Roeder, 1979). From the crude alkaloidal extracts the swansonine, calystegine B1, B2 and $\mathrm{C} 1$ were isolated (Fig. 1).

The alkaloids content of Ipomea fistulosa collected from differents regions is the same in all the sample plants. References do not exist in our country about the components of the Ipomea fistulosa nor of its danger or toxicity, either to the human or the cattle. In this work it was possible to isolate in the extracts, the alkaloids swansonine, calystegine $\mathrm{B}_{1}, \mathrm{~B}_{2}$ and $\mathrm{C}_{1}$ that were identified in other species of Ipomea, in other countries. This important information will put in alert the rural producer to eradicate these weeds in the pasture.

\section{Vibrational Analysis}

In Fig. 2 we display the IR spectrum obtained experimentally for the extracted sample. In the analyzed sample, it contains all the alkaloids. In the first stage of this study it was not possible to proceed to the separation of each one of them. In Table 1, we present experimental IR spectra as well the corresponding assignment of the different vibrational modes of the extracted sample.

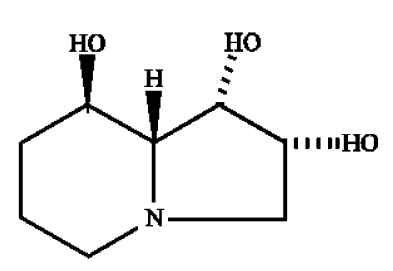

1

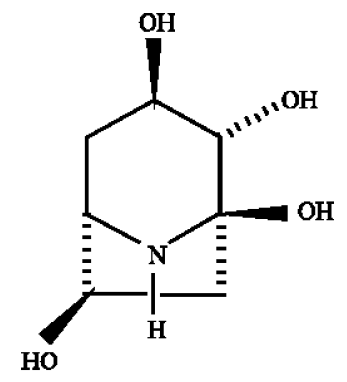

3

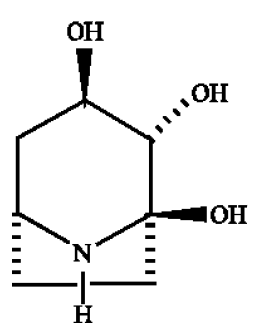

2

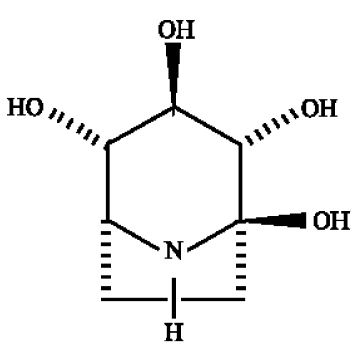

4

Fig. 1: Structure of alkaloids present in Ipomea fistyulosa: Swainsonine (1); Calistegines $A_{3}(2), B_{1}(3)$, $\mathrm{B}_{2}(4)$ 


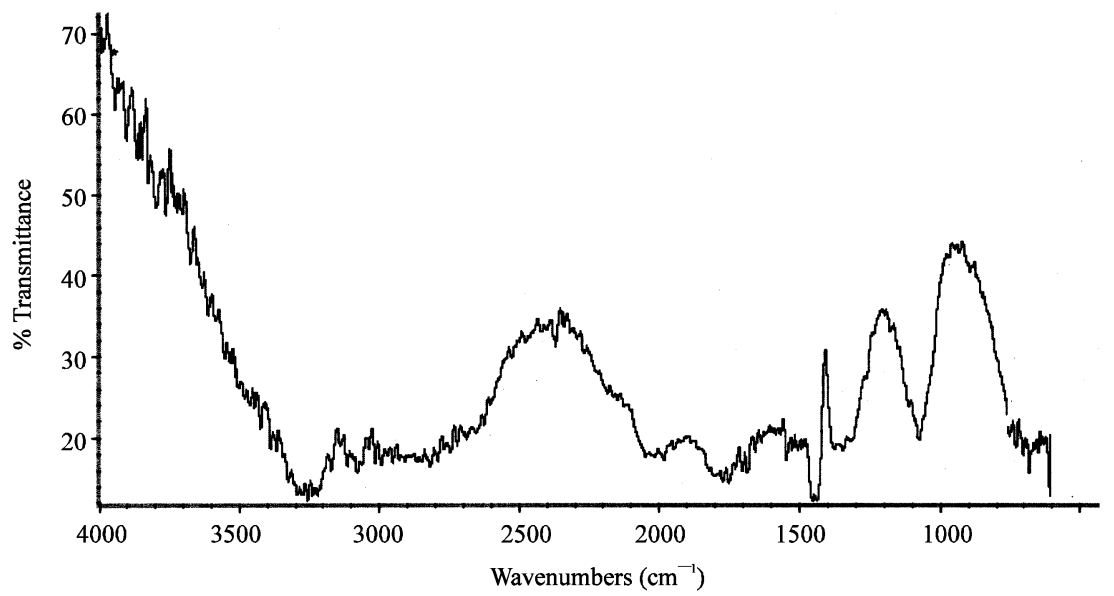

Fig. 2: Vibrational spectrum of the extracted sample

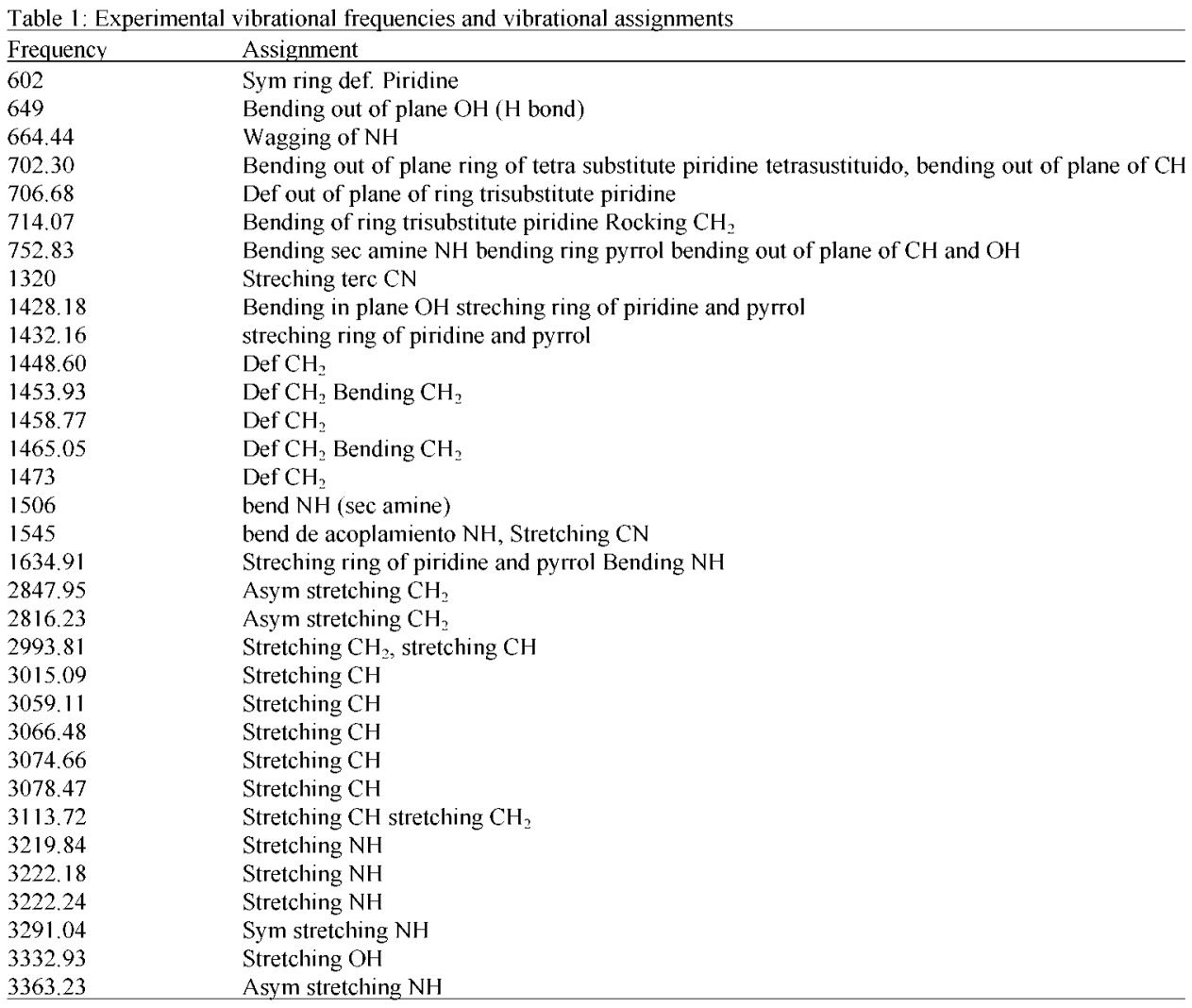

The $3363.23 \mathrm{~cm}^{-1}$ mode corresponds to the asymmetric stretching of NH of a secondary amine and the $3332.93 \mathrm{~cm}^{-1}$ band corresponds the stretching of the $\mathrm{OH}$ group. Bands between 3291.04 and $3219.84 \mathrm{~cm}^{-1}$ correspond to symmetrical stretching NH of a secondary amine.

In the range of $3215.03-2999.81 \mathrm{~cm}^{-1}$ we have the asymmetric stretching of the $\mathrm{CH}_{2}$. In the range $3113.72-2993.81 \mathrm{~cm}^{-1}$ appears the asymmetric stretching of the $\mathrm{CH}$ group. The band $2847.95 \mathrm{~cm}^{-1}$ corresponds to the symmetrical stretching of $\mathrm{CH}_{2}$ group. 
The asymmetric stretching of the ring of heterocyclic, pyridine and pyrrol appears at $1634.91 \mathrm{~cm}^{-1}$. The coupling between the $\mathrm{NH}$ and the $\mathrm{OH}$ is located at $1545.09 \mathrm{~cm}^{-1}$, like the stretching of $\mathrm{CN}$ group belonging to a secondary amine.

Bands at $1448.60-1473.32 \mathrm{~cm}^{-1}$ are assigned to $\mathrm{CH}$ bending and deformation of the $\mathrm{CH}_{2}$ group. Band at $1320 \mathrm{~cm}^{-1}$ corresponds to the stretching of the tertiary amine. The symmetrical stretching of the ring of heterocyclic, pyridine and pyrrol appears at $1432.16 \mathrm{~cm}^{-1}$. Band at 1428.18 corresponds to the bending (deformation) in the plane of the OH group.

Within the range between $752.83-702.30 \mathrm{~cm}^{-1}$ appear the characteristic groups enabling to identify to the alkaloids and they are deformation of the ring of pyrrol, deformation of the pyridine ring tetra and trisubstituted and deformation out the plane of $\mathrm{CH}$ and $\mathrm{OH}$ groups. Band at $664.44 \mathrm{~cm}^{-1}$ corresponds to the wagging of the NH group and the band appearing at $649.19 \mathrm{~cm}^{-1}$ corresponds to the deformation out the plane of the $\mathrm{OH}$ group.

\section{Conclusions}

Experimentally, we can conclude that we have found the alkaloids Calistegina $A_{3}, B_{1}$ and $B_{2}$ and Swansonina, using the method of extraction by soaking. Besides, we have determined the IR spectrum of the extracted sample and we have presented an assignment of the vibrational normal modes. In a second phase of this study, the four alkaloids will be separated by chromatography in column. Besides, each of them will be suitably characterized. Results will be presented elsewhere in the forthcoming future.

\section{References}

Amal, K., P. Sanjukta and M. Sudhendu, 1998. Protein profile of the allergenic pollen of lpomoea fistulosa L. A comparative study. Ann. Agric. Evirom. Med., 5: 131-134.

Austin, D.F., 1977. Ipomoea came Jacq. vs. Ipomoea fistulosa Mart Ex Choisy. Taxon. 26: 235-238.

de Balogh, M.K.K.I., A.P. Dimante, J.J. Van Der Lugt, R.J. Molyneux, T.W. Naudé and W.G. Welman, 1999. A lysosomal storage disease induced by Ipomea carnea in goats in Mozambique. J. Vet. Diagn. Invest., $11: 266-273$.

Haraguchi, M., S.L. Gorniak, K. Ikeda, Y. Minami, S. Kato, A.A. Watson, R.J. Nash, R.J. Molyneux and N. Asano, 2003. Alkaloidal components in the poisonous plants, Ipomoea carnea (Convolvulacea). J. Agric. Food Chem., 13;51: 4995-5000.

Hueza, I.M., M.L. Dagli, S.L. Gorniak and C.A. Paulino, 2003. Toxic effect of prenatal Ipomoea carnea administration to rats. Vet. Hum. Toxicol., 45: 298-302.

Hueza, I.M., J.L. Guerra, M. Haraguchi, A. Naoki and S.L. Gorniak, 2005. The role of alkaloids in Ipomoea carnea toxicosis; A study is rats. Exp. Toxicol. Pathol., 57: 53-58.

Ikeda, K., A. Kato, I. Adachi, M. Haraguchi and N. Asano, 2003. Alkaloids from the poisonous plant Ipomoea camea: Effects on intracellular lysosomal glycosidase activities in human lymphoblast cultures. Japan. J. Agric. Food Chem., 17;51: 7642-7646.

Lorenzi, H., 1991. Plantas danhinas do Brazil, Ipomoea fistulosa. Editora Plantarum, Soa Paulo.

Mendez, M.C. and F. Riet-Correa, 2000. Plantas Tóxicas e Micotoxicoses. Pelotas, Editora e Gráfica Universitária/UFPeI, Laboratório Regional de Diagnóstico, Facultade de Veterinária, pp: 112.

Molyneux, R.J., R.A. Mckenzy, B.M. O'Sullivan and A.D. Elbeind, 1995. Identification of the glycosidase inhibitors swansonine and calystegine B2 en Weir vine (Ipomoea calobra) and correlation with toxicity. California, USA. J. Nat. Prod., 58: 878-886.

Nath, I. and D.C. Pathak, 1995. Induced Ipomoea carnea toxicity in goats: Clinical and pathomorphological studies. Indian J. Vet. Pathol., 19: 50-52.

O’Donell, L., 1959. Revista de Botánica. Convolvuláceas Argentinas. Tomo, XXIX: 87-261.

Wiedenfeld, H. and E. Roeder, 1979. The pyrrolizidine alkaloid senecionine from Senecio fuchsia. Phytochemistry, 18: 1083-1084. 